Trinity University

Digital Commons @ Trinity

Psychology Faculty Research

Psychology Department

2010

\title{
The Suppressive Power of Positive Thinking: Aiding Suppression- Induced Forgetting in Repressive Coping
}

\author{
Paula T. Hertel \\ Trinity University, phertel@trinity.edu \\ L. McDaniel
}

Follow this and additional works at: https://digitalcommons.trinity.edu/psych_faculty

Part of the Psychology Commons

Publication Details

Cognition and Emotion

\section{Repository Citation}

Hertel, P.T., \& McDaniel, L. (2010). The suppressive power of positive thinking: Aiding suppression-induced forgetting in repressive coping. Cognition and Emotion, 24(7),1239-1249. doi: 10.1080/ 02699930903172377

This Article is brought to you for free and open access by the Psychology Department at Digital Commons @ Trinity. It has been accepted for inclusion in Psychology Faculty Research by an authorized administrator of Digital Commons@ Trinity. For more information, please contact jcostanz@trinity.edu. 


\title{
BRIEF REPORT
}

\section{The suppressive power of positive thinking: Aiding suppression-induced forgetting in repressive coping}

\author{
Paula Hertel and Leda McDaniel \\ Trinity University, San Antonio, TX, USA
}

\begin{abstract}
Participants scoring high and low on a measure of repressive coping style (Mendolia, 2002) first learned a series of related word pairs (cue-target). Half of the cues were homographs. In the subsequent think/no-think phase (Anderson \& Green, 2001), they responded with targets on some trials and suppressed thoughts of targets on others. Suppressed targets were always emotionally negative, as were targets associated with baseline cues reserved for the final test. Some participants were provided with emotionally benign or positive substitutes to help them suppress, and these substitutes were related to different meanings of the homographic cues, compared to those established by the targets. On the final test, all cues were presented for target recall. Only the repressors significantly benefited from the provision of positive substitutes to aid forgetting of the negative targets, regardless of the nature of the cues.
\end{abstract}

Keywords: Forgetting; Suppression; Repressive coping.

Change your thoughts and you will change your world.

(Peale, 1948, p. 233)

Norman Vincent Peale, the famous proponent of thinking positively, might indeed have recommended intentional suppression of negative thoughts as a means for changing one's "world", although he might not have believed that such suppression would result in forgetting. Unlike Peale, we do not recommend the development of a general repressive coping style (see Myers et al., 2008), but we are nevertheless intrigued by the idea that people who use such techniques should be skilled in the suppression-induced forgetting of negative material if given something more positive to think about instead.

Suppression-induced forgetting refers to poor performance on tests of remembering, following a series of attempts to suppress thoughts of the tobe-remembered material. It has been successfully demonstrated through the use of the think/nothink (TNT) paradigm developed by Anderson and Green (2001). The paradigm consists of three

Correspondence should be addressed to: Paula T Hertel, Department of Psychology, Trinity University, 1 Trinity Place, San Antonio, TX 78212, USA. E-mail: phertel@trinity.edu

Order of authorship was determined alphabetically.

C 2009 Psychology Press, an imprint of the Taylor \& Francis Group, an Informa business 
main phases. First, participants learn a series of cue-target pairs to a specified criterion of producing the target when given the cue alone. These pairs are usually words (e.g., stone cottage), although pictures have also been used (Depue, Banich, \& Curran, 2006; Depue, Curran, \& Banich, 2007). Next, in the TNT phase, some of the cues are presented for continued multiple attempts to recall the target ("think"). When other cues are presented (typically in a different font colour), participants attempt to suppress thoughts of - "not think" about - the target while continuing to attend to the cue; multiple trials of attempted suppression are performed. Still other cues are not presented at all in the TNT phase, because they are reserved for baseline trials in the third phase: final recall. In this final phase, regardless of previous instructions, participants are encouraged to recall all the originally learned targets in response to their cues. Anderson and Green's demonstrations of belowbaseline, suppression-induced forgetting on this test have been replicated by others (Anderson et al., 2004; Depue et al., 2006, 2007; Hertel \& Calcaterra, 2005; Joormann, Hertel, Brozovich, \& Gotlib, 2005, Joormann, Hertel, LeMoult, \& Gotlib, 2009; Wessel, Wetzels, Jelicic, \& Merckelbach, 2005), although failures to replicate have also been documented (e.g., Bulevich, Roediger, Balota, \& Butler, 2006).

One report that is sometimes cited as failing to replicate the forgetting effect was conducted by Hertel and Calcaterra (2005), using related words as cue-target pairings (in contrast to the more typical use of very weakly related words). Below baseline forgetting was clearly achieved in that study under certain conditions. Central to our current concerns was the condition in which participants were provided with thought substitutes to use on suppression trials. For example, the pairing of stone street was provided as a substitute for stone cottage. This was not the first evidence of substitute-aided suppression, however. In the first publication of experiments on "white-bear" suppression, Wegner, Schneider, Carter, and White (1987) showed that red Volkswagens helped their participants to suppress thoughts of white bears. Moreover, the lack of rebound in the subsequent expression phase suggests an effect somewhat analogous to forgetting. ${ }^{1}$

In a subsequent study on white-bear suppression (Wenzlaff, Wegner, \& Roper, 1988), dysphoric students sometimes reported voluntary substitution of another negative thought for a negative thought scheduled to be suppressed. More recently, Joormann et al. (2008) brought this possibility under experimental control by providing either positive or negative substitutes to encourage forgetting of emotionally negative targets. Participants diagnosed with major depressive disorder and non-depressed controls forgot more targets when aided by positive substitutes. In fact, only the positive substitutes were helpful to the non-depressed controls; the negative substitutes conferred no additional benefit. This experiment thereby provided initial evidence for the power of positive — or at least benign — thinking in suppression-induced forgetting. The current research was designed to explore further the utility of positive or benign substitutes in forgetting negative targets by using more meaningful material and by recruiting participants who might be particularly good at thinking positively in the service of forgetting negative material.

In recent years, several investigators have examined the relation between repressive coping style (Weinberger, Schwartz, \& Davidson, 1979) and measures of thought suppression in the context of the white-bear paradigm (Barnier, Levin, \& Maher, 2004; Geraerts, Merckelbach, Jelicic, \& Habets, 2007; Geraerts, Merckelbach, Jelicic, \& Smeets, 2006). These studies showed that repressors suppressed anxiety-related autobiographical memories more successfully than did low-anxious, high-anxious, and defensively

\footnotetext{
${ }^{1}$ Clearly, there are differences between the white-bear (WB) paradigm and the TNT paradigm. Among them is the fact that TNT controls the number of times the target is cued during the suppression phase whereas WB does not. And TNT requests suppression of multiple targets, compared to WB's request for just one. Here, we merely point to evidence that substitutes aid forgetting in both paradigms.
} 
high-anxious participants and that, furthermore, the repressors experienced less rebound of the suppressed thought during the following expression period. Because this outcome did not distinguish among the other three styles, in the current experiment we recruited students who scored low or high on a unidimensional measure of repressive coping: the Index of Self-regulation of Emotion (ISE; Mendolia, 2002; also see Myers, Brewin, \& Power, 1998). In a version of the TNT paradigm intended to correspond more closely to real-world events to be forgotten (see Hertel \& Calcaterra, 2005; Hertel \& Gerstle, 2003), we asked the students to learn related cue-target pairs by constructing mental images. (Materials used by Joormann et al., 2008, were weakly related noun pairs, and the participants were merely instructed to learn them.) Next, in the TNT phase, participants practised recalling 12 positive targets and suppressing 12 negative targets; another 12 negative targets were reserved for baseline. We predicted that suppression-induced forgetting on the final test would be aided by the provision of positive substitutes in the repressor group in particular, and that the benefit of substitutes would be greater for repressors than for controls.

A secondary purpose for the current experiment was to explore the mechanism for the effect. Does it occur because cues for remembering take on new meaning as a function of their association with a substitute thought? The cord that is connected to computer might not be the same cord as the one that is connected to suicide. As a first step in examining this account we varied the nature of materials, reasoning that homograph cues might show stronger effects of reinterpretation than would non-homograph cues. A court that is used for tennis clearly is not the court for obtaining a divorce.

\section{METHOD}

\section{Materials}

Word pairs. Each of 36 cue words (18 homographs and 18 non-homographs) was assigned both a negative and benign partner for use as target or substitutes, depending on rotation. All triplets are listed in the appendix. The 18 homograph triplets were organised into three sets of 6 . These sets were balanced on frequencies (Kucera \& Francis, 1967), forward strength of association from cue to target and to substitute (Nelson, McEvoy, \& Schreiber, 1998), and concreteness and emotional valence of targets and substitutes. Concreteness ratings were obtained from 21 students at Trinity University. Emotionality ratings were taken from the Affective Norms for English Words (ANEW; Bradley \& Lang, 1999) and from 25 students at Trinity. Homograph sets were also balanced on category forward associations, which was calculated by summing forward associations across all responses in the South Florida norms that shared the same interpretation for the homograph cue as each target or substitute (e.g., for the cue gag some of the negative associates were choke, mouth, vomit and some of the benign associates were joke, gift, laugh). Non-homograph triplets were treated the same way, with the exception of omitting category forward associations. An additional 6 non-homograph cues -5 with benign targets and 1 with a negative target and benign substitute - served as buffers and practice items.

Questionnaires. To identify repressors, we used the Index of Self-regulation of Emotion (ISE; Mendolia, 2002), which consist of two scales: the short form of the Taylor Manifest Anxiety Scale (MAS; Bendig, 1956) and the Marlowe-Crowne Social Desirability Scale (SDS; Crowne \& Marlowe, 1960); ISE $=20-($ MAS - SDS). High scores are produced by low anxiety and high social desirability (range $=0$ to 53 ). At the end of the session, we administered a questionnaire to obtain reports of non-compliance with suppression instructions and voluntary use of thought substitutes (see Hertel \& Calcaterra, 2005).

\section{Participants and design}

The final sample consisted of 72 undergraduate students ( 39 women, 33 men) enrolled in introductory 
psychology classes at Trinity University and participating as a course requirement. (An additional 6 students' data were set aside because they failed to meet learning criteria or guessed the role of homographs.) We recruited the students who scored highest (35 and above) and lowest (26 and below) on the ISE, administered as a separate task during class time. ISE scores from repressors $(M=$ $40.5, S D=3.36)$ and controls $(M=17.7, S D=$ 5.40) were at least as extreme as those in Mendolia's (2002) groups $\left(M=37.7\right.$ and 20.2, respectively). ${ }^{2}$ Experimenters were kept unaware of the participants' ISE scores.

Under a constraint of equal cell size, participants in each group were randomly assigned to either the aided or unaided condition of suppression and to one of three conditions for counterbalancing sets of materials with the instruction during the TNT phase (baseline, respond, suppress); the gender ratio varied only slightly across these conditions. Each condition of instruction was assigned one set of homograph and one set of non-homograph pairs, 12 pairs in all. Across participants in each group and suppression condition, each cue appeared equally often as a baseline cue, a cue to respond with the target, and a cue to suppress thoughts of the target. When cues were assigned to the respond instruction, they were paired with benign targets. Cues assigned to baseline and suppress instructions were paired with negative targets.

\section{Procedure}

All tasks were implemented with Superlab Pro software (Version 4.07; Cedrus Corporation, San Pedro, CA). The procedure was adapted from Hertel and Calcaterra (2005). All oral responses by participants were keyed by the experimenter.
Learning phase. Participants were alerted to a subsequent test and asked to form a mental image of each pair and to rate its vividness. Each pair appeared at the centre of the monitor in black font on a light grey background for $5 \mathrm{~s}$. After a $500 \mathrm{~ms}$ ISI, this display was followed by a scale for rating vividness from 1 (not vivid) to 7 (very vivid). Three filler pairs appeared at the beginning and three at the end of the learning phase, as buffers for the 36 experimental pairs.

Experimental pairs were ordered in a randomised-block design such that each block of six pairs contained one pair from each set (3 with homograph cues and 3 with non-homographs). Within each block, two of the pairs were benign (and would later be used in trials for responding during the TNT phase) and four of the pairs were negative (two of which would not be presented during TNT and two of which would serve as suppression trials). Order within blocks was randomised anew for each participant.

Immediately following the main task, learning was assessed. All 42 cues were each presented for a maximum of $5.2 \mathrm{~s}$ (depending upon the time of response), and participants were asked to recall the originally learned targets. At the end of each cue display, the correct target appeared in blue font and remained on the screen for $2 \mathrm{~s}$. Participants repeated this test up to four times until they correctly recalled at least four targets from each set of six assigned to baseline or suppression in the next phase (16 total). ${ }^{3}$

TNT phase. To assess their understanding of the TNT task, participants first completed a practice phase with the buffers from the learning phase. Cues signalling the requirement to respond with the target were displayed in green font; the one cue signalling suppression was shown in red (apple

\footnotetext{
${ }^{2}$ Repressors' scores ranged from 0 to 6 on the MAS and from 16 to 30 on the SDS. Participants' scores in the control group ranged from 1 to 19 on the MAS and 2 to 19 on the SDS.

${ }^{3}$ At the end of the learning phase and again following recall, participants were asked to rate their mood on four scales: depressed/happy, tense/relaxed, pessimistic/optimistic, distressed/not-distressed. On each test, ratings differed only according to group, with the repressors rating themselves as uniformly more positive, $p<.005$. All interactions with condition were nonsignificant, $p>.20$. Therefore, mood did not confound the results of our manipulation. Across conditions, all moods became slightly more negative (decreasing an average of 5 points on the 100-point scale) from the first to the second administration $(p<.006)$, and time did not interact significantly with suppression condition or group, $p>.18$.
} 
which was a cue for the target maggot). In the aided condition, participants were instructed to use the substitute word, orchard to help them not think about maggot. Following this practice, participants in the aided condition studied 12 substitutes for negative targets to be suppressed in the main TNT phase. Cue-substitute pairs were shown in black font for $5 \mathrm{~s}$ each, and participants read them aloud.

During the main TNT phase, cues were ordered in the same block design used in the learning phase, re-randomised, although the baseline cues were not presented. Twelve (green) cues for responding with benign targets were presented for a maximum of $3 \mathrm{~s}$ each on 12 different occasions. If participants did not recall the target during the allotted time, it was then displayed in blue font for $500 \mathrm{~ms}$. Another 12 (red) cues for suppressing negative targets from the learning phase were similarly presented for a full $3 \mathrm{~s}$ each, and participants were instructed to avoid saying or even thinking about the targets, while focusing on the cues. If they erroneously responded with the target, they saw a display of large red Xs for $500 \mathrm{~ms}$. All details of the TNT phase were kept constant across unaided and aided conditions, except: (a) participants in the aided condition were encouraged to think about and say the substitute that they had just learned (e.g., tennis in place of divorce in response to court); (b) aiding substitutes were presented in blue font for $500 \mathrm{~ms}$ following the offset of the cues (or the offset of Xs in the rare case of suppression errors).

Final test phase. The 6 buffer cues appeared first, followed by the 36 experimental cues according to the previous ordering scheme, with cues rerandomised within blocks. Each cue was displayed for $4 \mathrm{~s}$, and participants were encouraged to respond with the targets learned in the first phase. They were also told that if a second word came to mind they could report it as well. However, the experimenter emphatically requested recall of all targets, regardless of previous instructions. (When participants made more than one response for any cue, a second test was administered in which we read the two responses and asked them to choose the actual target.)

\section{RESULTS}

We first report results from two analyses, one performed on the percentage correct on the last learning test taken in order to meet the criterion (at least four targets recalled from the six each set assigned to baseline or suppression) and the more important analysis of the percentages of target words recalled on the final test. Each dependent measure was submitted to a mixed-design analysis of variance (ANOVA) with between-subjects factors for Group (controls vs. repressors) and Type of Suppression (unaided vs. aided) and within-subjects factors for Materials (homograph vs. non-homograph) and Instruction (suppress vs. baseline). The percentages of benign targets (from the respond condition of TNT) were not included because they were not relevant to the criterion for learning and because their recall was almost perfect on the final test $(M=99.9 \%)$. To reduce error variance we also included counterbalancing condition as a between-subjects factor in each analysis, but we do not report significant effects involving that factor. The Type I error rate was set at .05. To address concerns about power, we report all effects associated with $p<.10$.

\section{Initial learning}

The ANOVA performed on the percentage correct on the criterion learning test revealed only a trend for non-homograph pairs to be learned better than homograph pairs $(M=87 \%$ vs. $85 \%)$; however, this effect was not significant, $F(1,60)=3.21, M S E=119.14, p=.078, \eta^{2}=$ .05 . For all other effects, $p>.11$. Therefore, we can infer that differences in final recall of words should not be attributed to initial learning differences between groups or conditions.

\section{Final test}

Table 1 presents the means and standard deviations for the full design in the main analysis of

COGNITION AND EMOTION, 2010, 24 (7) 
Table 1. Mean percentages of targets recalled on the final test (standard deviations)

\begin{tabular}{lccccc}
\hline & \multicolumn{2}{c}{ Controls } & & \multicolumn{2}{c}{ Repressors } \\
\cline { 2 - 3 } \cline { 5 - 6 } & Unaided & Aided & & Unaided & Aided \\
\hline Homograph & & & & \\
$\quad$ Suppress & $77.7(30.7)$ & $81.3(18.0)$ & & $84.2(17.6)$ & $75.1(19.1)$ \\
$\quad$ Baseline & $87.5(21.8)$ & $94.4(9.9)$ & & $89.7(11.6)$ & $90.6(10.3)$ \\
Non-homograph & & & & \\
$\quad$ Suppress & $83.3(21.3)$ & $83.3(12.7)$ & & $87.9(13.7)$ & $74.9(24.3)$ \\
Baseline & $94.4(9.9)$ & $88.8(12.7)$ & & $93.4(10.2)$ & $96.2(7.3)$ \\
\hline
\end{tabular}

Note: $n=18$.

percentage of targets recalled on the final test. We found the same non-significant trend for nonhomograph targets to be better recalled, $F(1$, $60)=3.17, \quad M S E=169.92, \quad p=.080, \eta^{2}=.05$, and non-significant interactions of materials with other factors $(p>.14)$. As expected, suppressed targets were recalled less frequently than baseline $(M=81 \%$ vs. $92 \%$, respectively), $F(1$, $60)=33.22, M S E=258.32, p<.001, \eta^{2}=.36$. No other factors approached significance $(p>.12)$, with the exception of the three-way interaction between Group, Suppression Condition, and Instruction, $F(1,60)=3.41, M S E=$ 258.32, $p=.070, \eta^{2}=.05$.

In line with our hypothesis regarding the benefit of substitutes for repressors, the data were analysed separately within each group. As shown in Figure 1, controls produced similar below-baseline suppression across aided and unaided conditions $(F<1.0$ for the simple interaction); the simple main effect of Instruction was the only significant effect, $F(1$, $30)=10.60, M S E=330.23, p=.003, \eta^{2}=.26$. Repressors also experienced below-baseline forgetting, but it was greater in the aided condition, as revealed by the significant simple interaction of Suppression Condition by Instruction, $F(1$, $30)=8.02, \quad M S E=186.41, \quad p=.008, \quad \eta^{2}=.21$. Moreover, this effect did not depend on the nature of materials $(F<1.0)$; repressors successfully used substitutes to aid forgetting no more effectively in response to homograph cues than to non-homographs.

Next, we examined evidence for below-baseline forgetting in each combination of Group and Suppression Condition. Recall differences between baseline and suppressed targets were significant in each combination except the controls in the unaided condition, $t(17)=1.73, S E=$ $6.015, p=.101$. However, the correlation among the suppression effect and the ISE scores in the unaided condition neared $0.0 ; r(34)=-.06, p=$ $.728{ }^{4}$ We cannot conclude that repressors were more successful than controls in that condition.

\section{Self-reports}

Self-reported non-compliance with suppression instructions during the TNT phase did not reveal significant differences according to Suppression Condition or Group. Responses were averaged across the first three items on the post-experimental questionnaire. These items assessed how often the participant used strategies on suppression trials such as checking to make sure they still knew the target before or after not thinking about it. Participants were generally quite

\footnotetext{
${ }^{4}$ One control participant in the unaided condition produced a baseline-suppression difference of $83.3 \%$, a difference greater than $3 S D$ from the mean of all differences in both unaided conditions and one that established the large error variance in that condition. The correlation of the suppression effect with ISE scores in the unaided condition remained close to 0.0 when those data were removed from the analysis, $r(33)=.04, p=.795$.
} 


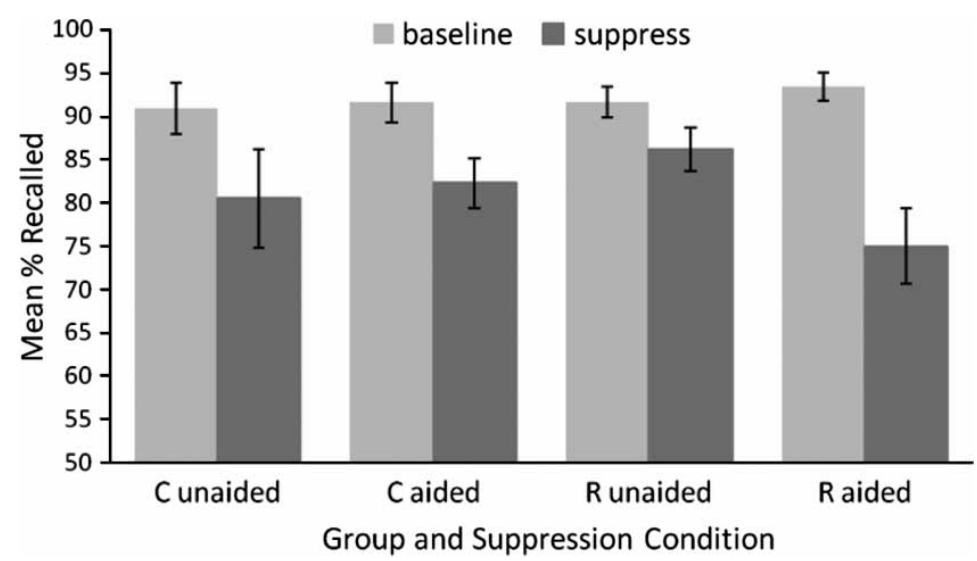

Figure 1. Mean percentage of targets recalled, regardless of the type of cue, according to group $(C=$ control, $R=$ repressor $)$ and suppression condition (unaided and aided).

compliant; the overall mean of 0.87 was less than an answer of "rarely". Reported voluntary use of substitutes in the unaided condition was generally frequent $(M=3.3$, where $3=$ frequently and $4=$ very frequently), and there was a marginally significant trend for repressors to report more frequent use, $t(34)=2.01, S E=0.304, p=.052$; $M=3.6$ vs. 3.0 .

\section{DISCUSSION}

Our aim in designing this experiment was to evaluation whether students with stronger tendencies toward repressive coping could forget emotionally negative targets more successfully if they entertained benign thoughts in response to cues that had previously brought the negative targets to mind than if they merely tried not to think about them. This prediction was supported. This finding of aided forgetting, however, was no more extreme when the meaning of the cues underwent a transformation through association with the benign substitutes, as was the case with homographs, than when the cues' meanings shifted less dramatically, as was true for nonhomographs. Also, benign substitutes did not promote greater below-baseline forgetting by controls, compared to their attempts at unaided suppression. In general, however, final recall of negative targets was impaired by prior suppression attempts.

The failure to find benefits from experimentally provided substitutes in the control group was the first result of its kind. Hertel and Calcaterra (2005) found significant effects of emotionally neutral substitutes in aiding the forgetting of neutral targets (both related to the cues) by both dysphoric and non-dysphoric students, and Joormann et al. (2009) found significant effects of positive substitutes for negative targets (which were unrelated to their cues). Joormann et al. even found benefits from negative substitutes if the participants were clinically depressed. In speculating about the cause of the present failure, we considered the fact that the control group included anxious participants. Attentional bias to and failure to disengage from emotionally negative material are well documented features of anxiety (see Fox, Russo, Bowles, \& Dutton, 2001; Mathews \& MacLeod, 2005). The TNT suppression task has a lot in common with attentional tasks that rely on disengagement, at least on early suppression trials. Thus, one possibility is that benign substitutes in competition with negative targets were less attention grabbing for the controls. A reasonable approach to evaluating this possibility would involve participants identified as either low or high anxious at the outset.

COGNITION AND EMOTION, 2010, 24 (7) 
Ideally, future experiments on repressive forgetting in this paradigm should classify participants according to the four categories identified by Weinberger et al. (1979), especially for the purpose of evaluating anxiety-related differences. In this first attempt with the TNT paradigm, our use of a continuum approach (ISE) was motivated in part by the difficulty of carrying out the design with full counterbalancing within four groups, as well as by the literature on suppression and repressive coping that revealed no differences among the three categories of non-repressors (Barnier et al., 2004; Geraerts et al., 2006). In general, continuum methods, like the fourcategory method, have consistently demonstrated that repressors report low anxiety while simultaneously exhibiting high levels of physiological arousal (e.g., Coifman, Bonanno, Ray, \& Gross, 2007; Pauls \& Stemmler, 2003). On the other hand, Derakshan, Myers, Hansen, and O'Leary (2004) found that defensiveness alone predicted spontaneous, uninstructed suppression of thoughts about an emotionally negative film, regardless of anxiety levels. In short, the combinations of defensiveness, self-reported anxiety, and actual arousal are important considerations in future experiments on suppression-induced forgetting.

Other individual-difference variables might also be related in systematic ways to performance in the TNT paradigm. Because hypotheses regarding dysphoria were not central to our concerns in this experiment, our participants were not categorised according to their level of dysphoria. Nevertheless, due to the typical relation between scores on self-reports of anxiety and dysphoria, we assume that the majority of repressors were not dysphoric and therefore similar to the control participants in the experiment by Joormann et al. (2009). According to this line of speculation, we predict that the use of negative substitutes would be less successful for repressors. In fact, Joormann et al.'s findings provide the only justification of which we are aware that positive thinking is more powerful than negative thinking in the service of forgetting negative material. Yet repressive coping and depression do not always misalign in studies of remembering. For example, Raes, Hermans, Williams, and Eelen (2006) found that participants who produced fewer specific autobiographical memories in response to negative cues also produced higher ISE scores and better coping on a subsequent task. Furthermore, depressed individuals typically generate fewer specific memories on the AMT (Williams et al., 2007).

Our experiment was also designed to address mechanisms for the effects of substitutes on forgetting. How do the substitutes work? As pointed out by others (Bulevich et al., 2006; Hertel \& Calcaterra, 2005), the provision of substitutes corresponds to the $\mathrm{A}-\mathrm{D}$ phase in a retroactive-interference paradigm for paired-associate learning (Barnes \& Underwood, 1959). In fact, we have recently found that the separate contribution of substitutes to forgetting, above effects of target suppression, has its counterpart in paired-associate learning in an experiment by Delprato and Garskof (1969). In that paradigm as well as in the TNT paradigm, we speculated, substitutes might cause forgetting of targets through retroactive interference because they induce changes in the functional meaning of the cue.

This cue-reinterpretation account, based on classic theories of encoding variability (e.g., Martin, 1968) and encoding specificity (Tulving \& Thomson, 1973), was tested in the present experiment by varying the degree of change in cue meaning as a function of the identity of the associate (target or substitute). Half of our cues were homographs, and the corresponding targets and substitutes were related to their different interpretations. Shivde and Anderson (2001) had found that retrieval-induced forgetting (RIF) of targets related to homograph cues was facilitated by practising recall of words associated with alternative meanings. Our substitution paradigm, by virtue of its similarity to the RIF paradigm, should produce stronger substitution effects for the homograph cues, due to the greater change in meaning induced by substitutes, compared to the change with non-homograph cues. We found no support for this hypothesis. One possible reason, consistent with older views of encoding variability and potentially testable in subsequent 
experiments, is that the change in meaning for non-homograph cues was sufficient to establish the effect. Perhaps the cord connected to the computer is truly a different cord from the one used to commit suicide.

A final issue raised by our results concerns below-baseline forgetting in the unaided conditions. According to Derakshan, Eysenck, and Myers (2007), the suppression of negative thoughts should be relatively automatic in repressive copers. Indeed, our repressors produced evidence of below-baseline forgetting in the unaided condition; however they did not forget more successfully than did the controls. In the first study to demonstrate forgetting of negative experimental materials according to repressivecoping style, Myers et al. (1998) used the directed-forgetting paradigm; compared to others, repressors recalled fewer negative words from the to-be-forgotten list. Our findings appear at first to conflict with that result; however, it is important to consider that the directed-forgetting paradigm invites a more passive process of focusing attention on the upcoming items to be remembered, compared to the process of active target suppression in the unaided TNT condition. Indeed, the directed-forgetting paradigm and the aided-TNT condition have in common a focus on other concepts in the service of forgetting previously learned targets. More generally, it is not clear whether skill in automatic suppression is even relevant to performance in tasks that demand intentional suppression without providing external substitutes. Repressors seemed to have an edge in suppressing autobiographical memories in the white-bear paradigm (Barnier et al., 2004; Geraerts et al., 2006, 2007; cf., Derakshan et al., 2004), but this paradigm is not the best for investigations of forgetting.

We conclude by returning to the two main findings in this report. First, this experiment replicated the effect of suppression-induced forgetting without the use of aids, at least in the group of repressors. As far as we know, it is the first to do so with meaningfully related and emotional cue-target pairs (although a similar trend was reported by Hertel \& Gerstle, 2003).
The second main finding is that repressors did indeed forget emotionally negative targets more effectively when provided with emotionally benign substitutes. Clearly, further research is necessary in order to determine whether the effect would also obtain with targets and substitutes of other emotional valences. Because positive memories are cherished, understanding how they might be intentionally forgotten has little applied value, but such investigations are important in order to evaluate any claim that positive or benign thinking is more helpful than negative thinking in repressors' forgetting of negative events. We also recommend further research designed to explore the basis for repressors' skill in using substitutes and suspect that their superior cognitive control plays an important role (see Geraerts et al., 2007).

In the introduction, we noted our reticence in recommending a repressive coping style in general, but in closing we are tempted to recommend the use of benign substitutes in forgetting emotionally negative events. Our tentative recommendation is restricted to situations in which specific cues lead to specific non-traumatic yet negative memories. After the negative memory has been milked for all of its clinical value, there is little point in continuing to entertain it. In this respect, Norman Vincent Peale might have been right in advising (some of) us to think positively.

Original manuscript received 27 April 2009 Revised manuscript received 2 July 2009 Accepted revision received 7 July 2009 First published online 21 August 2009

\section{REFERENCES}

Anderson, M. C., \& Green, C. (2001). Suppressing unwanted memories by executive control. Nature, 410, 366-369.

Anderson, M. C., Ochsner, K. N., Kuhl, B., Cooper, J., Robertson, E., Gabrieli, S. W., et al. (2004). Neural systems underlying the suppression of unwanted memories. Science, 303, 232-235.

Barnes, J. M., \& Underwood, B. J. (1959). "Fate" of first-list associations in transfer theory. Journal of Experimental Psychology, 58, 97-105.

COGNITION AND EMOTION, 2010, 24 (7) 
Barnier, A. J., Levin, K., \& Maher, A. (2004). Suppressing thoughts of past events: Are repressive copers good suppressors? Cognition and Emotion, 18, 513-531.

Bendig, A. W. (1956). The development of a short form of the Manifest Anxiety Scale. Journal of Consulting Psychology, 20, 384.

Bradley, M. M., \& Lang, P. J. (1999). Affective norms for English words (ANEW). Gainesville, FL. The NIMH Center for the Study of Emotion and Attention, University of Florida.

Bulevich, J. B., Roediger, H. L., III, Balota, D. A., \& Butler, A. C. (2006). Failures to find suppression of episodic memories in the think/no-think paradigm. Memory E Cognition, 34, 1569-1577.

Coifman, K. G., Bonanno, G. A., Ray, R. D., \& Gross, J. J. (2007). Does repressive coping promote resilience? affective-autonomic response discrepancy during bereavement. Journal of Personality and Social Psychology, 92, 745-758.

Crowne, D. P., \& Marlowe, D. A. (1960). A new scale of social desirability independent of psychopathology. Journal of Consulting Psychology, 24, 349-354.

Delprato, D. J., \& Garskof, B. E. (1969). Unlearning in the absence of new learning. Journal of Verbal Learning and Verbal Behavior, 8, 388-392.

Depue, B. E., Banich, M. T., \& Curran, T. (2006). Suppression of emotional and nonemotional content in memory: Effects of repetition on cognitive control. Psychological Science, 17, 441-447.

Depue, B. E., Curran, T., \& Banich, M. T. (2007). Prefrontal regions orchestrate suppression of emotional memories via a two-phase process. Science, 317, 215-219.

Derakshan, N., Eysenck, M. W., \& Myers, L. B. (2007). Emotional information processing in repressors: The vigilance-avoidance theory. Cognition and Emotion, 21, 1585-1614.

Derakshan, N., Myers, L. B., Hansen, J., \& O’Leary, M. (2004). Defensiveness and attempted thought suppression of negative material. European Journal of Personality, 18, 521-535.

Fox, E., Russo, R., Bowles, R., \& Dutton, K. (2001). Do threatening stimuli draw or hold visual attention in subclinical anxiety? Journal of Experimental Psychology: General, 130, 681-700.

Geraerts, E., Merckelbach, H., Jelicic, M., \& Habets, P. (2007). Suppression of intrusive thoughts and working memory capacity in repressive coping. American Journal of Psychology, 120, 205-218.
Geraerts, E., Merckelbach, H., Jelicic, M., \& Smeets, E. (2006). Long term consequences of suppression of intrusive anxious thoughts and repressive coping. Behaviour Research and Therapy, 44, 1451-1460.

Hertel, P. T., \& Calcaterra, G. (2005). Intentional forgetting benefits from thought substitution. Psychonomic Bulletin E Review, 12, 484-489.

Hertel, P. T., \& Gerstle, M. (2003). Depressive deficits in forgetting. Psychological Science, 14, 573-578.

Joormann, J., Hertel, P. T., Brozovich, F., \& Gotlib, I. H. (2005). Remembering the good, forgetting the bad: Intentional forgetting of emotional material in depression. Journal of Abnormal Psychology, 114, 640648.

Joormann, J., Hertel, P. T., LeMoult, J., \& Gotlib, I. H. (2009). Training forgetting of negative material in depression. Journal of Abnormal Psychology, 118, 34-43.

Kucera, H., \& Francis, W. N. (1967). Computational analysis of present-day American English. Providence, RI: Brown University Press.

Martin, E. (1968). Stimulus meaningfulness and paired associate transfer: An encoding variability hypothesis. Psychological Review, 75, 421-441.

Mathews, A., \& MacLeod, C. (2005). Cognitive vulnerability to emotional disorders. Annual Review of Clinical Psychology, 1, 167-195.

Mendolia, M. (2002). An index of self-regulation of emotion and the study of repression in social contexts that threaten or do not threaten selfconcept. Emotion, 2, 215-232.

Myers, L. B., Brewin, C. R., \& Power, M. J. (1998). Repressive coping and the directed forgetting of emotional material. Journal of Abnormal Psychology, 107, 141-148.

Myers, L. B., Burns, J. W., Derakshan, N., Elfant, E., Eysenck, M. W., \& Phipps, S. (2008). Current issues in repressive coping and health. In A. Vingerhoets, I. Nyklícek, \& J. Denollet (Eds.), Emotion regulation: Conceptual and clinical issues (pp. 69-86). New York: Springer.

Nelson, D. L., McEvoy, C. L., \& Schreiber, T. A. (1998). The University of South Florida word association, rhyme, and word fragment norms. (Available from: http://www.usf.edu/FreeAssociation/)

Pauls, C. A., \& Stemmler, G. (2003). Repressive and defensive coping during fear and anger. Emotion, 3, 284-302.

Peale, N. V. (1948). A guide to confident living. Englewood Cliffs, NJ: Prentice-Hall. 
Raes, F., Hermans, D., Williams, J. M. G., \& Eelen, P. (2006). Reduced autobiographical memory specificity and affect regulation. Cognition and Emotion, 20, 402-429.

Shivde, G., \& Anderson, M. C. (2001). The role of inhibition in meaning selection: Insights from retrieval-induced forgetting. In D. S. Gorfein (Ed.), On the consequences of meaning selection: Perspectives on resolving lexical ambiguity (pp. 175190). Washington, DC: American Psychological Association.

Tulving, E., \& Thomson, D. M. (1973). Encoding specificity and retrieval processes in episodic memory. Psychological Review, 80, 352-373.

Wegner, D. M., Schneider, D. J., Carter, S. R., \& White, T. L. (1987). Paradoxical effects of thought suppression. Journal of Personality and Social Psychology, 53, 5-13.

Weinberger, D. A., Schwartz, G. E., \& Davidson, R. J. (1979). Low-anxious, high-anxious, and repressive coping styles: Psychometric patterns and behavioral and physiological responses to stress. Journal of Abnormal Psychology, 88, 369-380.

Wenzlaff, R. M., Wegner, D. M., \& Roper, D. W. (1988). Depression and mental control: The resurgence of unwanted negative thoughts. Journal of Personality and Social Psychology, 55, 882-892.

Wessel, I., Wetzels, S., Jelicic, M., \& Merckelbach, H. (2005). Dissociation and memory suppression: A comparison of high and low dissociative individuals' performance on the think-no think task. Personality and Individual Differences, 39, 1461-1470.

\section{APPENDIX}

\section{Cue-target triplets}

\begin{tabular}{|c|c|c|c|c|c|}
\hline \multicolumn{3}{|c|}{ Homographs } & \multicolumn{3}{|c|}{ Non-homographs } \\
\hline Cue & Negative target & Positive target & Cue & Negative target & Positive target \\
\hline slip & mistake & dress & wagon & massacre & toy \\
\hline plot & murder & story & tower & killer & church \\
\hline sentence & prison & paragraph & chair & execution & cabinet \\
\hline stalk & victim & celery & butter & fat & pancakes \\
\hline punch & face & bowl & mushroom & poison & pizza \\
\hline patient & hospital & calm & highway & accident & travel \\
\hline terminal & cancer & airport & ketchup & blood & bottle \\
\hline treat & gash & candy & trunk & corpse & doll \\
\hline stern & teacher & yacht & lamp & nightmare & wish \\
\hline pelt & stones & covering & clock & bomb & radio \\
\hline court & divorce & tennis & fork & wounds & dinner \\
\hline stroke & brain & caress & skyscraper & terrorist & snow \\
\hline lie & cheat & bed & museum & rape & taxi \\
\hline ram & wreck & ewe & spray & pest & perfume \\
\hline mug & wallet & coffee & hotel & whore & party \\
\hline cast & bone & audition & runner & tornado & swimmer \\
\hline wake & coffin & sunrise & cord & suicide & computer \\
\hline gag & vomit & laugh & fabric & lice & art \\
\hline
\end{tabular}

